\title{
Propagação vegetativa por estaquia de serigueleira (Spondias purpurea L.) com diferentes concentrações de ácido indolbutírico
}

\author{
Andressa Fabiane Faria de Souza ${ }^{1}$, Marcondes Geraldo Coelho Junior ${ }^{1 *}$, Janne Kety de Souza Nogueira ${ }^{1}$, \\ Eduardo Carvalho da Silva Neto ${ }^{1}$, Acacio Geraldo de Carvalho ${ }^{1}$
}

\begin{abstract}
RESUMO: Dentre as espécies pertencentes ao gênero Spondias, destaca-se a serigueleira (Spondias purpurea L.) cultivada empiricamente em pomares domésticos e que apresenta grande potencial de exploração econômica. O objetivo deste trabalho foi avaliar o efeito de quatro concentrações de ácido indolbutírico (AIB) (0; 2000; 4000 e 8000 ppm) na formação de raízes em diferentes tipos de estacas (herbáceas, semilenhosas e lenhosas) de serigueleira. O tratamento de estacas de serigueleira com ácido indolbutírico nas concentrações de 2000 e 4000 ppm aumenta a formação de calo, raiz e brotação. As estacas semilenhosas e lenhosas apresentaram os melhores resultados para a formação de tecido caloso, enraizamento e brotação. O AIB pode ser utilizado como indutor do enraizamento em estacas de Spondias purpurea L..

Palavras-chave: regulador de crescimento, estaquia, auxina sintética, propagação vegetativa.

\section{Vegetative propagation by cuttings in Spondias purpurea $\mathbf{L}$. with different concentrations of indolbutyric acid}

\begin{abstract}
Among the species belonging to the genus Spondias, it is worth mentioning the serigueleira (Spondias purpurea L.) cultivated empirically in domestic orchards and that presents great potential for economic exploitation. The objective of this work was to evaluate the effect of four concentrations of indolbutyric acid (IBA) $(0,2000,4000$ and $8000 \mathrm{ppm}$ ) on root formation on different types of vegetable cuttings (herbaceous, woody and semi-woody) of serigueleira (Spondias purpurea L.). The treatment of serigueleira cuttings (Spondias purpurea L.) with indolbutyric acid at concentrations of 2000 and $4000 \mathrm{ppm}$ increases the formation of callus, root and budding. The woody and semi woody cuttings presented the best results for the formation of calluses, roots and sprouts. The IBA can be used as inducer of rooting in cuttings of Spondias purpurea $\mathrm{L}$..

Key-words: growth regulator, cutting, synthetic auxin, vegetative propagation.
\end{abstract}

\section{INTRODUÇÃO}

O gênero Spondias, pertence à família Anacardiaceae, tem 18 espécies, das quais seis ocorrem no Brasil (LIMA \& MELEIRO, 2012). São árvores frutíferas tropicais em domesticação e exploradas pelo seu valor comercial (ENGELS et al., 2012). Dentre as espécies pertencentes ao gênero Spondias, destaca-se a seriguela (Spondias purpurea L.) cultivada empiricamente em pomares domésticos (SANTOS et al., 2011).

Originária da América Central distribui-se desde o México até o Norte do Peru e Brasil, considerada endêmica em regiões semiáridas (FORTUNYFERNÁNDEZ, 2017). É uma das espécies mais cultivadas do gênero Spondias que produz frutos pequenos e avermelhados, com polpa aromática de sabor agridoce (SANTOS et al., 2011). A fruta "seriguela" vem ganhando importância econômica devido às indústrias de sucos e bebidas, e desenvolvimento de tecnologias que auxiliam no manejo pós-colheita (MALDONADO-ASTUDILLO et al., 2014). Além disso, tem sido muito utilizada contra diversas doenças e sintomas como diabetes, colesterol e diarreia (NASCIMENTO, CONCEIÇÃO, 2011; FREITAS et al., 2012).

Tosta et al. (2012) reiteram que o crescente interesse dos consumidores por frutos tropicais, aliado ao número cada vez maior de pequenas indústrias de processamento de frutas para produção de polpa podem tornar os produtos derivados de Spondias um rentável negócio agrícola. No entanto, há necessidade de se desenvolver pesquisas para solucionar alguns problemas tecnológicos relacionados a essa espécie para cultivá-la em escala comercial (LIMA \& MELEIRO, 2011), pois, apesar do controle total dos fatores ambientais na indústria de propagação moderna, altas perdas econômicas ocorrem devido a um enraizamento insuficiente (VELOZA et al., 2014; HUSEN et al., 2017). 
A produção de mudas do gênero Spondias para a implantação de pomares deve ser feita por via vegetativa: por estaquia ou enxertia (ALMEIDA et al., 2017). A propagação vegetativa por estaquia utiliza caules, raízes ou folhas para a confecção de estacas com o objetivo de preservar no novo indivíduo as características encontradas na planta mãe (PIMENTA et al., 2017). Assim, a estaquia pode ser classificada como um método bastante rápido de propagação assexuada de baixo custo, o qual permite a manutenção das características das plantas de interesse agronômico, evitando assim a mistura de espécies (SILVA et al, 2014).

A propagação de espécies de difícil enraizamento pode ser superada se fornecidas condições ótimas para o enraizamento, em especial, os reguladores vegetais (ALMEIDA et al., 2017). O conhecimento das melhores técnicas de propagação vegetativa, aliadas às substâncias que promovem aumento no enraizamento, contribuem para melhorar a utilização de espécies com ganhos de produtividade (XAVIER et al., 2011).

Na propagação vegetativa por estaquia, é comum o tratamento das estacas com auxinas sintéticas para estimular a emissão de raízes e aumentar a produção de mudas em menor espaço de tempo, com maior número e maior vigor das raízes, além de aumentar a uniformidade do enraizamento. Entre os reguladores de crescimento, as auxinas são as empregadas com maior frequência (LIMA et al., 2016). Um exemplo de auxina é o ácido indolbutírico (AIB), tido como uma auxina sintética mais estável e menos solúvel que a auxina endógena, ácido indolacético (AIA), sendo considerado um dos melhores estimuladores do enraizamento (RIOS et al., 2012). Além disso, não é tóxico para a maioria das plantas, mesmo em altas concentrações (LONE et al., 2010).

Dado o grande potencial econômico da serigueleira (Spondias purpurea L.) e considerando a escassez de abordagens científicas na literatura sobre a sua propagação vegetativa por estaquia, objetivou-se avaliar o efeito de quatro concentrações de ácido indolbutírico (AIB) $(0 ; 2000 ; 4000 ; 6000$ e 8000 ppm) na formação de raízes em diferentes tipos de estacas (herbáceas, semilenhosas e lenhosas) de serigueleira (Spondias purpurea L.).

\section{MATERIAL E MÉTODOS}

O estudo foi desenvolvido em casa de vegetação no campus da Universidade Federal Rural do Rio de Janeiro (UFRRJ), no município de Seropédica - RJ. O clima atual da região, segundo Köppen, é do tipo Aw, quente e úmido sem inverno pronunciado, com período chuvoso no verão e uma estiagem não muito rigorosa no inverno.
As estacas de serigueleira (Spondias purpurea L.) foram obtidas de plantas do campus da universidade, com aproximadamente sete anos de idade. Foram selecionados aleatoriamente ramos sadios dos quais se obteve três tipos de estacas em relação ao estádio de desenvolvimento, todos com $15 \mathrm{~cm}$ de comprimento: estacas herbáceas (subapicais sem folhas) e estacas semilenhosas (terço mediano sem folhas) e estacas lenhosas (terço basal, sem folhas). Todas as estacas foram cortadas em bisel e, em seguida, imersas, em solução do fungicida Benomyl a $0,2 \%$, durante 10 segundos. Para o tratamento das estacas com AIB as estacas foram colocadas com a base na solução-tratamento $(0,2000,4000$ e 8000 ppm) por 10 segundos, sendo posteriormente plantadas na profundidade equivalente a $1 / 3$ do seu tamanho em canteiros contendo areia lavada, sob nebulização intermitente.

O delineamento experimental utilizado foi o de blocos completamente casualizados, com três repetições, sendo cada parcela constituída de 10 estacas. As estacas foram avaliadas ao longo de três semanas, registrando-se os seguintes parâmetros: número de estacas com brotações, formação de tecido caloso e formação de raízes (número de raízes emitidas).

Para isso, as estacas foram cuidadosamente retiradas do substrato, sem prejudicar sua formação e, contou-se, uma por uma, o aparecimento ou não das variáveis anteriormente mencionadas, e depois colocadas novamente no substrato até a próxima avaliação, em que os possíveis danos nas raízes foram desprezíveis entre uma avaliação e outra, pois esta espécie apresenta raízes robustas que facilitam uma avaliação não destrutiva. Posteriormente, foi calculada a percentagem de cada estaca em relação ao total, referente ao número de estacas que apresentaram as variáveis em estudo.

De início, se avaliou o efeito da concentração de AIB e da época de avaliação em relação ao percentual de formação de calo, raiz e brotação independentemente do tipo de estaca utilizado (herbácea, semilenhosa e lenhosa). Ao final do experimento $\left(3^{a}\right.$ semana) procedeu-se a uma outra avaliação sobre o efeito da concentração de AIB e do tipo de estaca em relação ao percentual de formação de calo, raiz e brotação das plantas.

Os dados foram submetidos a análise de normalidade por meio do teste Shapiro-Wilk e à análise de regressão para os tratamentos quantitativos sendo os modelos escolhidos com base na significância do coeficiente de regressão $\left(\mathrm{R}^{2} \geq\right.$ $0,80)$, tratados em linguagem $R$ (2009). Os efeitos das variáveis foram verificados pelo teste $\mathrm{F}$ ( $5 \%$ de probabilidade). 


\section{RESULTADOS E DISCUSSÃO}

Foi observada interação significativa na formação de calo, raiz e brotação em relação à época de avaliação e às diferentes concentrações de ácido indolbutírico (AIB) (Figura 1).

Na primeira semana de avaliação, as estacas que receberam o tratamento de $4000 \mathrm{ppm}$ apresentaram as maiores médias percentuais de formação de calo, raiz e brotação. Destaca-se assim que em relação a formação de calo, verificou-se a tendência de surgimento desses até mesma concentração (4000 ppm), também na primeira semana, com média de $48,4 \%$. A partir da segunda semana, os tratamentos $2000 \mathrm{ppm}$ e $4000 \mathrm{ppm}$ apresentaram médias estatisticamente superiores aos demais tratamentos para todos os parâmetros avaliados.
Desde a década de 1980, Alvarenga \& Carvalho (1983), já apontavam que o estímulo ao enraizamento se dá até uma determinada concentração de AIB, diferente para cada espécie, a partir da qual o efeito passa a ser inibitório. Isso poderia explicar os menores valores observados nas estacas que receberam o tratamento de $8000 \mathrm{ppm}$.

De acordo com Taiz et al. (2016) as auxinas sintéticas induzem o alongamento celular e alteram as atividades fisiológicas da planta, e dependendo da concentração, inibe ou estimula o crescimento e a diferenciação dos tecidos, existindo um nível ótimo para estas respostas fisiológicas, o que está diretamente relacionado aos níveis endógenos dessas substâncias.
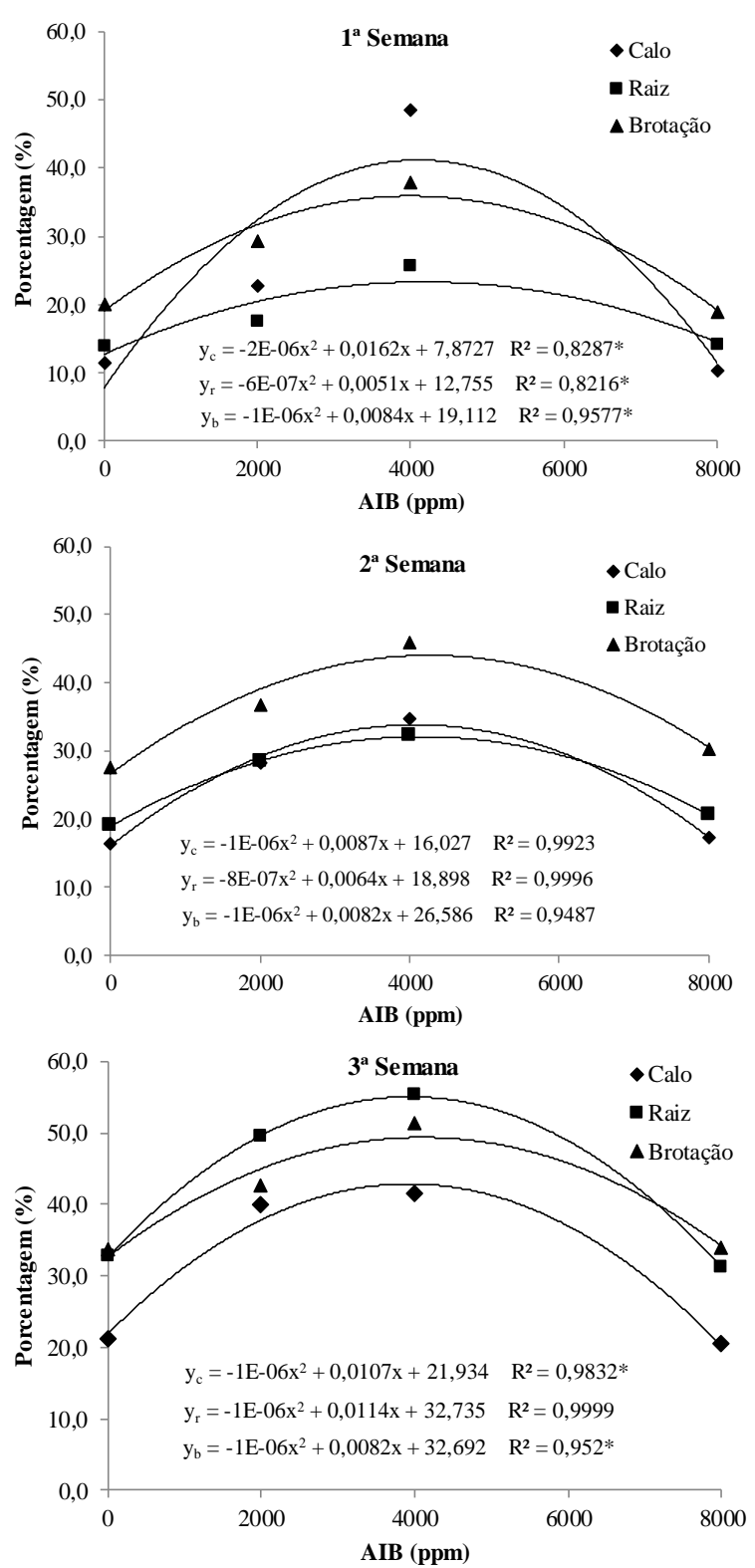

Figura 1 - Equação de regressão ajustada para o percentual de formação de calo, raiz e brotação em serigueleira (Spondias purpurea L.) em função das diferentes concentrações de $\operatorname{AIB}\left(0,2000,4000,6000\right.$ e 8000 ppm) e da época de avaliação $\left(1^{\mathrm{a}}, 2^{\mathrm{a}}\right.$ e $3^{\mathrm{a}}$ semana). *Valores significativos ao nível de $5 \%$ de probabilidade ( $\mathrm{p}$-valor $<0,05$ ). 
Em estudo avaliando a propagação vegetativa de cajarana (Spondias sp.) tratadas com ácido indolbutírico em diferentes concentrações, Tosta et al. (2012) confirmam que a utilização de AIB aumenta o número de brotos, comprimento dos brotos, número de folhas, número de folíolos, comprimento do sistema radicular, porcentagem de estacas enraizadas, número de raízes por estaca, massa seca da folha, massa seca da brotação, massa seca do sistema radicular e a relação entre a massa seca das brotações e a massa seca do sistema radicular. Ainda de acordo com os mesmos autores, vários trabalhos evidenciam respostas positivas na produção de estacas de espécies de Spondias à aplicação de AIB (COELHO, 2001; SOUZA et al., 2001; RIOS et al., 2012). No entanto, ainda há divergência em relação a dose ideal de fitoregulador a ser utilizado.

Deve-se enfatizar que a emissão de brotos em estacas nem sempre indica sucesso no processo de propagação por estaquia (ALMEIDA et al., 2017). Véras et al. (2017) relataram que o declínio na porcentagem de brotos e no comprimento de brotações em estacas de cajá amarelo (Spondias mombin L.), ocorre à medida que as doses de AIB aumentam, isso porque altas doses de ácido indolbutírico pode ter efeito citotóxico. Além disso, existe uma correlação inversamente proporcional entre o comprimento do broto e o enraizamento, sendo que o surgimento de brotos pode reduzir o enraizamento, pois eles drenam os nutrientes do corte.

Almeida et al. (2017) ressaltam que a utilização de AIB pode uniformizar e melhorar o desenvolvimento inicial de mudas, contribuindo de modo significativo para o enraizamento em condições naturais. Rios et al. (2012), relataram que o número de raízes por estacas aumentou à medida que houve o acréscimo das concentrações de AIB, onde o maior número de raízes por estacas de umbuzeiro ocorreu na concentração de 6000 ppm.

Com relação à avaliação dos tipos de estaca e concentrações de ácido indolbutírico (AIB), os tratamentos também apresentaram diferenças significativas para a formação de calo, raiz e brotação (Figura 2). Para as estacas semilenhosas e lenhosas observou-se padrão semelhante, onde os tratamentos 2000 ppm e 4000 ppm apresentaram médias estatisticamente superiores para a formação de calo, raiz e brotação. Também, pode ser observada a tendência a mudança de comportamento quanto ao efeito do AIB a partir de 4000 ppm, conforme ilustrado nas linhas de regressão.
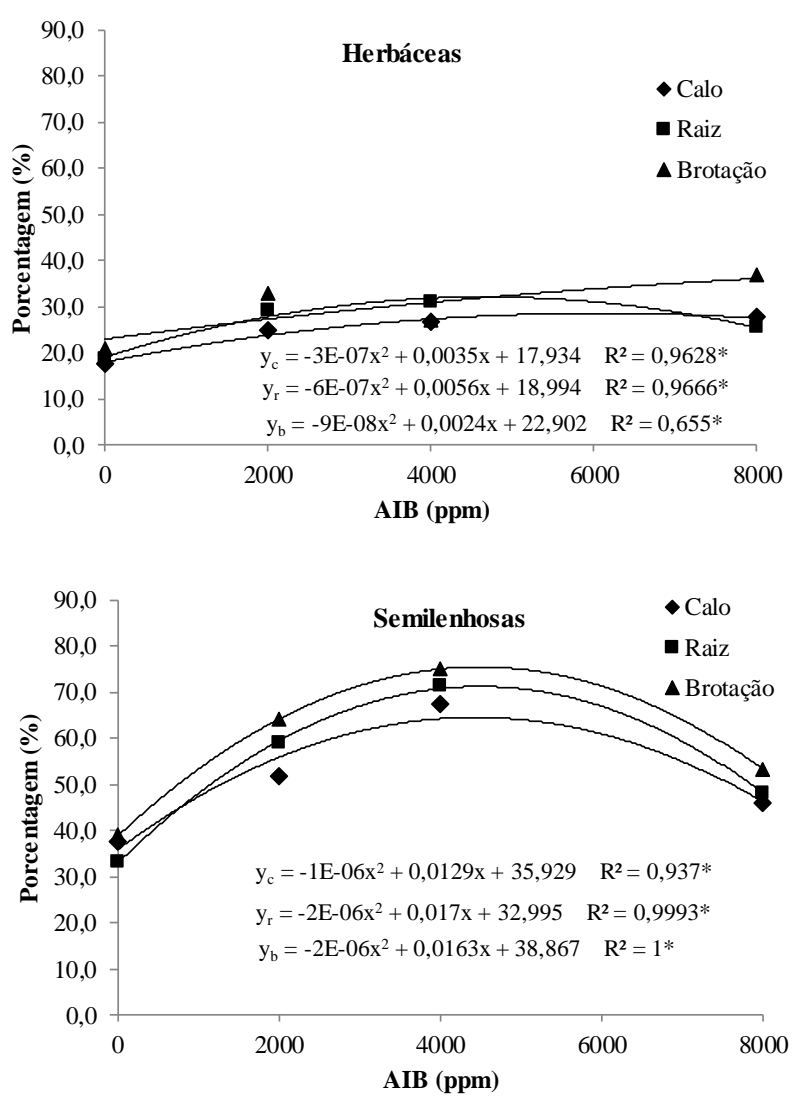


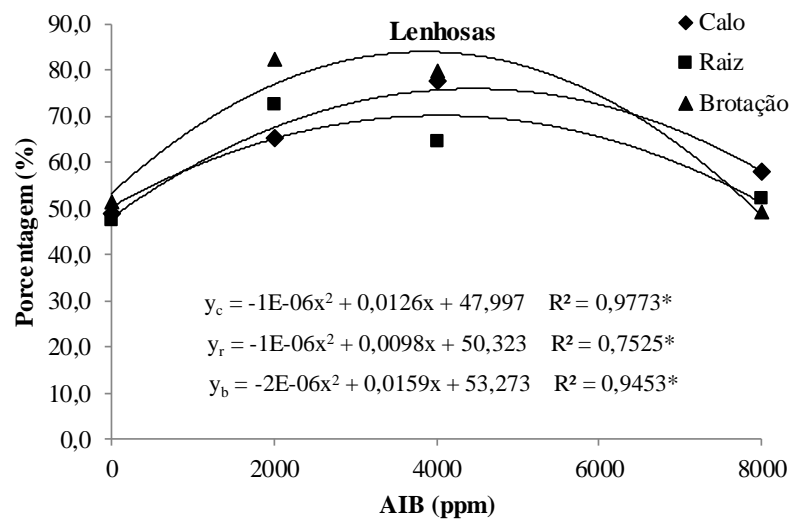

Figura 2 - Equação de regressão ajustada para o percentual de formação de calo, raiz e brotação em serigueleira (Spondias purpurea L.) em função das diferentes concentrações de AIB (0, 2000, 4000, 6000 e 8000 ppm) e dos tipos de estaca (herbáceas, semilenhosas e lenhosas). *Valores significativos ao nível de $5 \%$ de probabilidade (p-valor $<0,05$ ).

Apesar das divergências de respostas expressas em literatura, os resultados encontrados nesse estudo permitem concluir que o AIB pode ser utilizado como indutor do enraizamento em estacas de serigueleira (Spondias purpurea L.), sendo as estacas semilenhosas e lenhosas as mais indicadas no método de propagação por estaquia, em virtude de apresentarem maior grau de lignificação, o que as torna menos perecíveis e facilita o manuseio e o transporte (HARTMANN et al., 2011).

\section{CONCLUSÕES}

O tratamento de estacas de serigueleira (Spondias purpurea L.) com ácido indolbutírico nas concentrações de 2000 e 4000 ppm aumenta a formação de calo, raiz e brotação. As estacas semilenhosas e lenhosas apresentaram os melhores resultados para a formação de tecido caloso, enraizamento e brotação. O AIB pode ser utilizado como indutor do enraizamento em estacas de Spondias purpurea $\mathrm{L}$.

\section{REFERÊNCIAS}

ALMEIDA, J. P. N.; LEITE, G. A.; MENDONÇA, V.; CASTRO FREITAS, P. S.; ARRAIS, I. G.; SILVA TOSTA, M. Concentrações de AIB e substratos no enraizamento e vigor de estacas lenhosas de cajaraneira. Revista de Ciências Agrárias, Belém, v. 60, n. 1, p. 1118. 2017.

ALVARENGA, L. R.; CARVALHO, V. D. Uso de substâncias promotoras de enraizamento de estacas frutíferas. Informe Agropecuário, Belo Horizonte, v. 9, n. 101, p. 47-55, 1983.

BASTOS, D. C.; PIO, R.; SCARPARE FILHO, J. A.; LIBARDI, M. N.; ALMEIDA, L. F. P.; GALUCHI, T. P. D.; BAKKER, S. T. Propagação da pitaya vermelha por estaquia. Ciência e Agrotecnologia, Lavras, v. 30, n. 6, p. 1106-1109, 2006.
COELHO, J. K. S. Enraizamentos de estacas verdes enfolhadas de cajarana (Spondeas sp). 2001. Monografia (Graduação em Agronomia) - Escola Superior de Agricultura de Mossoró, Mossoró.

ENGELS, C.; GRATER, D.; ESQUIVEL, P.; JIMENEZ, V. M.; GANZLE, M. G.; SCHIEBER, A. Characterization of phenolic compounds in jocote (Spondias purpurea L.) peels by ultra-high-performance liquid chromatography/electrospray ionization mass spectrometry. Food Research International., Burlington, v. 46, n. 2, p. 557-562, 2012.

FERRIANI, A. P.; BORTOLINI, M. F.; ZUFFELLATORIBAS, K. C.; KOEHLER, H.S. Propagação vegetativa de estaquia de azaleia arbórea (Rhododendron thomsonii HOOK. f.). Semina: Ciências Agrárias, Londrina, v. 27, n. 1, p. 35-42, 2006.

FORTUNY-FERNÁNDEZ, N. M.; FERRER, M. M.; RUENES-MORALES, M. R. Centros de origen, domesticación y diversidad genética de la ciruela mexicana, Spondias purpurea (Anacardiaceae). Acta Botanica Mexicana, Pátzcuaro, v. 121, p. 7-38, 2017.

FREITAS, A. V. L.; COELHO, M. F. B.; MAIA, S. S. S.; AZEVEDO, R. A. B. Plantas medicinais: um estudo etnobotânico nos quintais do Sítio Cruz, São Miguel, Rio Grande do Norte, Brasil. Revista Brasileira de Biociêcias, Porto Alegre, v. 10, n. 1, p. 48-59, 2012.

GOMES, W. A.; ESTRELA, M. A.; MENDONÇA, R. M. N.; SILVA, S. M.; SOUZA, A. P.; ALVES, R. E. Enraizamento de estacas de umbu-cajazeira (Spondias spp.). Procedings of the Interamerican Society for Tropical Horticulture, Boca Chica, v. 47, n. 1, p. 231233, 2005.

HARTMANN; H. T.; KESTER, D. E.; DAVIES JUNIOR, F. T. Plant Propagation: principles and practices. $8^{\mathrm{a}}$ ed. New York: Englewood Clipps: PrenticeHall, 2011. 647 p.

HUSEN, A.; IQBAL, M.; SIDDIQUI, S. N.; SOHRAB, S. S.; MASRESHA, G. Effect of indole-3-butyric acid on clonal propagation of mulberry (Morus alba L.) stem 
cuttings: rooting and associated biochemical changes. Proceedings of the National Academy of Sciences, India Section B: Biological Sciences, Nova Deli, v. 87, n. 1 , p. 161-166. 2017.

LIMA, I. C. G. S.; MELEIRO, C. H. A. Desenvolvimento, avaliação físico-química e sensorial de geleia e doce de corte de seriguela (Spondias purpurea $L$.) visando o crescimento da cadeia produtiva do fruto. Boletim do CEPPA, Curitiba, v. 30, n. 2, p. 221-232, 2012.

LIMA, D. M.; KLEIN, A. W.; SALLA, V. P.; MOURA, A. P. C.; DANNER, M. A. Ácido indolbutírico no enraizamento de estacas de Langerstroemia indica em diferentes substratos. Pesquisa Florestal Brasileira, Colombo, v. 36, n. 88, p. 549-554, 2016.

LONE, A. B.; UNEMOTO, L. K.; YAMAMOTO, L. Y.; COSTA, L.; SCHNITZER, J. A.; SATO, A. J.; RICCE, W. S.; ASSIS, A. M.; ROBERTO, S. R. Enraizamento de estacas de azaleia (Rhododendron simsii Planch.) no outono em AIB e diferentes substratos. Ciência Rural, Santa Maria, v. 40, n. 8, p. 1720-1725, 2010.

MALDONADO-ASTUDILLO, Y. I.; ALIA-TEJACAL, I.; NÚÑEZ-COLÍN, C. A.; JIMÉNEZ-HERNÁNDEZ, J.; PELAYO-ZALDÍVAR， C.; LÓPEZ-MARTÍNEZ， V.; VALLE-GUADARRAMA， S. Postharvest physiology and technology of Spondias purpurea L. and S. mombin L. Scientia Horticulturae, Victoria, v. 174, p. 193-206. 2014.

NASCIMENTO, J. M.; CONCEIÇÃO, G. M. Plantas medicinais e indicações terapêuticas da comunidade quilombola Olho D’água do Raposo, Caxias, Maranhão, Brasil. BioFar. Campina Grande, v. 6, n. 2, p. 138-151, 2011 ,

PIMENTA, A. C.; AMANO, E.; ZUFFELLATO-RIBAS, K. C. Estaquia e anatomia caulinar de Annona crassiflora Mart. Caderno de Ciências Agrárias, Montes Claros, v. 9, n. 2, p. 1-7, 2017.

R DEVELOPMENT CORE TEAM (2009). R: A language and environment for statistical computing. $\mathrm{R}$ Foundation for Statistical Computing, Vienna, Austria. ISBN 3-900051-07-0, URL http://www.R-project.org.

RIOS, E. S.; PEREIRA, M. C.; SANTOS, L. S.; SOUZA, T. C.; RIBEIRO, V. G. Concentrações de ácido indolbutírico, comprimento e época de coleta de estacas, na propagação de umbuzeiro. Revista Caatinga, Mossoró, v. 25, n. 1, p. 52-57, 2012.

SANTOS, T. C.; AMORIM, G. M.; BONOMO, R. C. F.; FRANCO, M. Determinação da atividade de CMCase e FPase da estipe fúngica Rhizopus sp. através da bioconversão do resíduo de seriguela (Spondias purpurea L.). Científica Ciências Biológicas e da Saúde, Londrina, v. 13, n. 3, p. 145- 149, 2011.
SILVA, C. A.; COSTA, P. R.; DETONI, J. L.; ALEXANDRE, R. S.; CRUZ, C. D.; SCHMILDT, O.; SCHMILDT, E. R. Divergência genética entre acessos de cajazinho (Spondias mombin L.) no norte do Espírito Santo. Revista Ceres, Viçosa, v. 61, n. 3, p. 362-369, 2014.

SOUZA, A. A.; REZENDE, L. P.; CÂMARA, F. A. A. Obtenção de mudas de Spondias sp pelo método de estaquia lenhosa e semi-herbáceas. In: SEMINÁRIO DE INICIAÇÃO CIENTIFICA, 7., 2001, Mossoró. Anais... Mossoró: CNPq/PIBIC/ESAM, 2001. p. 30-34.

TAIZ, L.; ZEIGER, E.; MOLLER, I. M.; MURPHY, A. Fisiologia e desenvolvimento vegetal. 6. ed. Porto Alegre: Artmed, 2016. 888 p.

TOSTA, M. S.; OLIVEIRA, C. V. F.; FREITAS, R. M. O.; PORTO, V. C. N.; NOGUEIRA, N. W.; TOSTA, P.A. F. Ácido indolbutírico na propagação vegetativa de cajaraneira (Spondias sp.). Semina, Londrina, v. 33, n. 1, p. 2727-2740, 2012.

VELOZA, C.; DURÁN, S.; MAGNITSKIY, S.; LANCHEROS, H. Rooting ability of stem cuttings of Macleania rupestris Kunth AC Sm., a South American fruit species. International journal of fruit science, San Diego, v. 14, n. 4, p. 343-361, 2014.

VÉRAS, M. L. M.; MENDONÇA, R. M. N., RAMIRES, C. M. C.; SILVA, S. M; PEREIRA, W. E. Effect of ethephon and indolebutyric acid on yellow mombin propagation via cutting. Pesquisa Agropecuária Tropical, Goiânia, v. 47, n. 4, p. 416-423, 2017.

XAVIER, A.; WENDLING, I.; SILVA, R. L. Silvicultura clonal: princípios e técnicas. Universidade Federal de Viçosa, 2a ed, 2013. 279 p. 